Surgery Journal 6(1): 4-6, 2011

ISSN: $1816-3211$

(C) Medwell Journals, 2010

\title{
Quantitative Evaluation of Arthroscopic Subacromial Decompression via MRI and its Consistency with Clinical Status in Patients with Chronic Impingement
}

\author{
Omer Selim Yildirim \\ Department of Orthopedic and Traumatology, Faculty of Medicine, \\ Ataturk University, 25240 Erzurum, Turkey
}

\begin{abstract}
The objective of the present study was to evaluate the relationship between subacromial distance measures before and after Arthroscopic Subacromial Decompression (ASD) using MRI and clinical status in patients with chronic impingement. Forty patients with chronic impingements at stage two and three were evaluated using UCLA shoulder scale and the Constant-Murley shoulder assessment and their subacromial distances were measured using MRI before ASD. They were monitored for 27.3 months (12-48) after ASD. The same evaluations and measurements were obtained at the end of the follow-up period. The initial and final subacromial distances were different (8.32 (5-12) vs. 11.90 (8-14) mm, respectively). The Constant-Murley shoulder assessment and UCLA shoulder scale scores also increased from 15.55-72.40 and from 8.10-30.95, respectively. Wilcoxon signed rank test confirmed statistical improvement in all these variables upon ASD $(\mathrm{p}<0.05)$. In this study, clinical remission was associated with the subacromial distance elongation in patients with chronic impingement upon ASD.
\end{abstract}

Key words: Chronic impingement, subacromial distance, artroscopic subacromial decompression, MRI, patients, Turkey

\section{INTRODUCTION}

Patient age, physical activity level and functional status of the affected shoulder are considered when conservative treatment or surgical intervention is choosen in patients with chronic impingement. Recently, Arthroscopic Subacromial Decompression (ASD) has been employed successfully in the treatment of patients with chronic impingement who are unresponsive to conservative therapies. Thank to arthroscopy, success rate of acromioplasty in shoulder surgery (Atalar et al., 2001). These surgical interventions are aimed to decompress subacromial region and consequently to prevent rotator cuff tension by relaxing it. The objective of this clinical study was to evaluate, the relationship between subacromial distance measures before and after ASD using MRI and clinical status in patients with chronic impingement.

\section{MATERIALS AND METHODS}

Twenty-two male and eighteen women with chronic impingement at the age of 49.6 (39-76) constituted the study population. Before ASD, shoulders of all patients were evaluated using MRI sagittal sections at $30^{\circ}$ abduction when shoulder impingement was noted most (Fig. 1a). They were also evaluated using UCLA shoulder

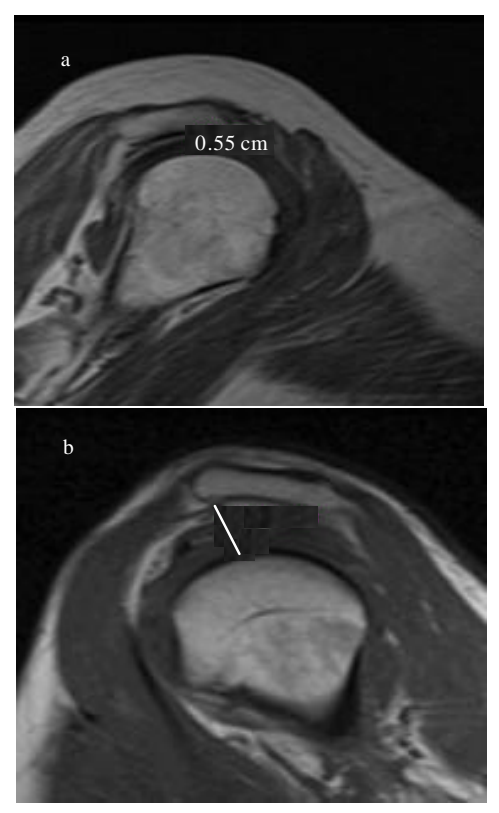

Fig. 1: The subacromial distance (a) before and (b) after ASD

scale and the Constant-murley shoulder assessment. Following administration of interskalen block anesthesia, all patients were subjected to subacromial decompression and coracoacromial connective tissue resection 
artroscopically at beach chair position. Total 4 days after $\mathrm{ASD}$, the patients were referred to physical theraphy. The patients were followed 27.3 (12-48) months after ASD. At the end of the final check-up MRI measurement (Fig. 1b) and evaluation tests were repeated. Data were subjected to descriptive statistics including normal distribution, frequency, mean and standard deviations. Data obtained before and after ASD were compared using Wilcoxon signed rank test (SPSS, Version 16.0, Chicago, IL). At 95\% confidence interval, statistical significance was considered when $\mathrm{p}<0.05$.

\section{RESULTS AND DISCUSSION}

Before $\mathrm{ASD}$, the coracohumeral distances were 8.32 (5-12) and $10.36 \mathrm{~mm}(8-12)$ in affected and healthy shoulders, respectively $(\mathrm{p}<0.05)$. The UCLA shoulder scale and the Constant-Murley shoulder assessment scores were $8.10(0-25)$ and $15.55(2-52)$, respectively (Fig. 2a and 3a). In the final check-up after ASD, the mean
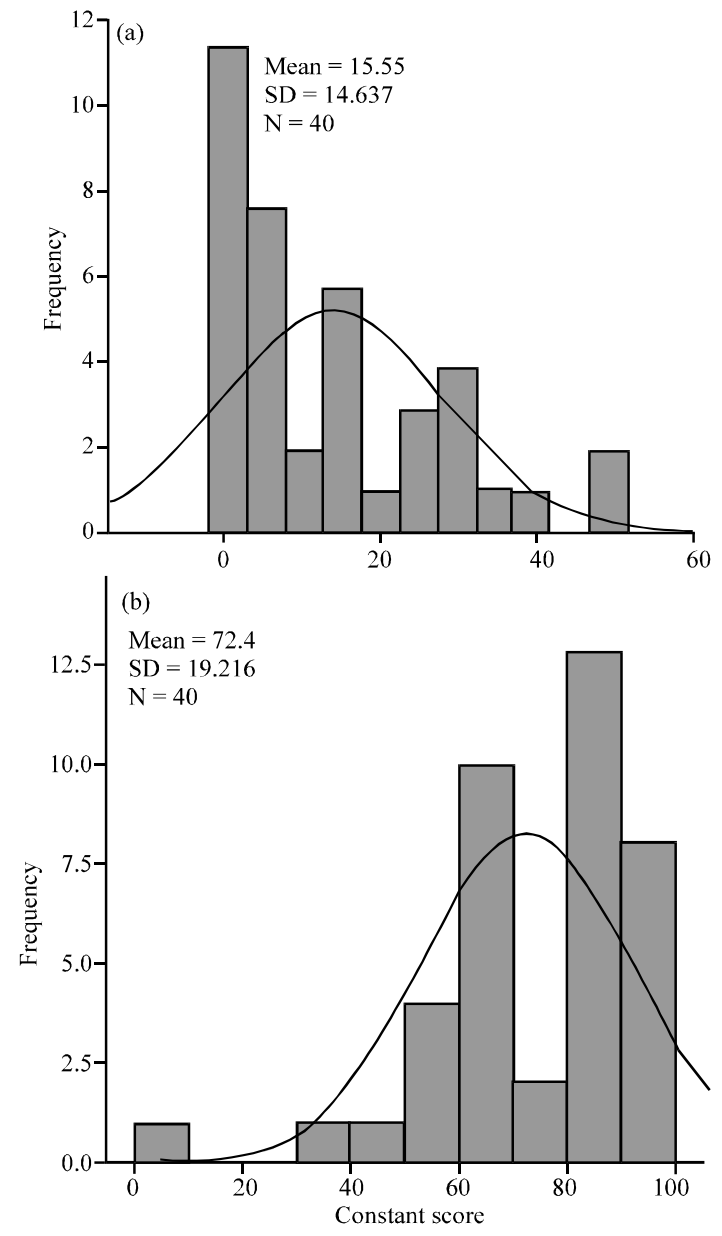

Fig. 2: The Constant-Murley shoulder assessment score (a) before and (b) after ASD coracohumeral distance, the UCLA Shoulder scale score and the Constant-Murley shoulder assessment score were was $11.90(8-14), 30.95(7-35)$ and $72.40(2-90) \mathrm{mm}$, respectively (Fig. 2b and $3 b$ ). Relative to ASD, shoulder measurements and evaluation scores improved statistically ( $p<0.05$ for all). Namely, the subacromial distance and clinical status improved significantly with ASD (Table 1). Chronic impingement, resulting from rotator cuff entrapment in the subacromial region is characterized by shoulder pain and activity limitation. Neer (1972) defined impingement syndrome and proposed

Table 1: Changes in the subacromial distance and clinical status relative to

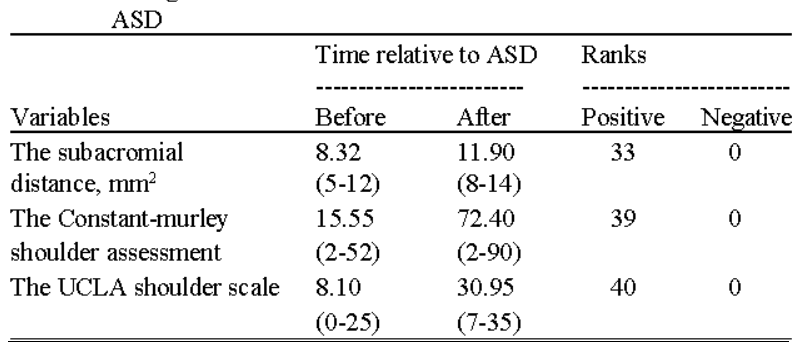
$\mathrm{p}<0.05$
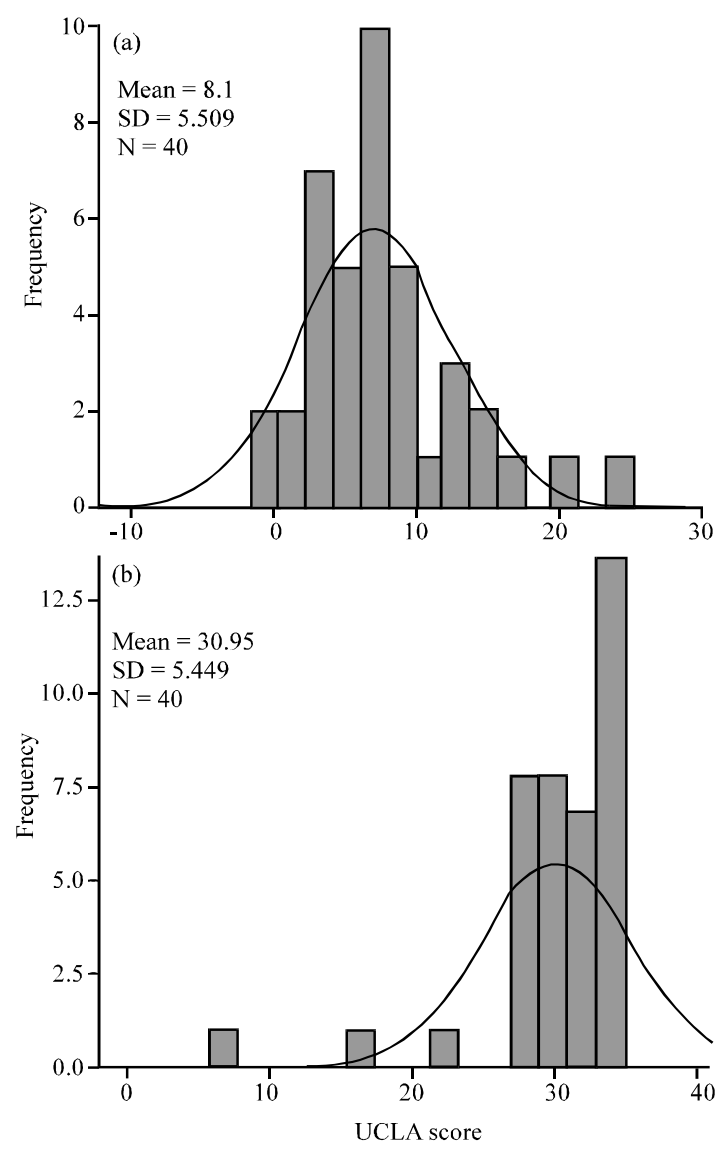

Fig. 3: The UCLA Shoulder scale score (a) before and (b) after ASD 
open acromioplasty for treatment in 1970s. Later, acromioplasty and subacromial decompression were considered effective interventions for the chronic impingement cases in which conservative approaches failed (Neer, 1983).

In the present study, the subacromial distance in affected shoulder was shorter than healthy one before ASD ( 8.3 vs. $10.3 \mathrm{~mm}, \mathrm{p}<0.05$ ). The subacromial distance, the Constant-Murley shoulder assessment score and the UCLA shoulder scale score increase significantly from $8.32-11.90,15.55-72.40$ and $8.10-30.95 \mathrm{~mm}$, respectively at the end of averaging 27.3 months follow-up $(\mathrm{p}<0.05)$ (Table 1).

Subacromial bursa compression, effective decompression and regular exercise after ASD could also contribute to clinical remission. Distance between acomion where is the insertion of supraspinatus tendon and caput humeri is $9-10 \mathrm{~mm}$ in the frontal position (Jobe, 1998).

If this distance is $<6 \mathrm{~mm}$, it is indication of subacromial impingement. In compassion of the subacromial distance in unaffected and affected shoulder, the distance was reported to range from 7-13 $\mathrm{mm}$ (Golding, 1962). Radiology and pathology studies ascertain that changes in the subacromial distance resulted from rotator cuff rupture (Cotton and Rideout, 1964).

In fact, the subacromial distance in intact rotator cuff is $6-14 \mathrm{~mm}$ whereas, it is measured as $1-4 \mathrm{~mm}$ in full layer rotator muscle rupture (Cotton and Rideout, 1964). In an early similar study, it was reported that the distance between acromion and caput humeri was $7-14$ and $<5 \mathrm{~mm}$ distance could indicate rotator muscle rupture (Weiner and Macnab, 1970). The degree of decompression is important in open or arthroscopic interventions. Lateral complete or radical acromionectomy causes continuation of complaints and deltoid insufficiency (Bezer et al., 2004). The ideal acromial resection amount is not known but resection of $0.9-2.0 \mathrm{~cm}$ in depth and $1.1 \mathrm{~cm}$ in length is suggested. Atalar et al. (2001) suggested $33 \mathrm{~mm}$ decompression at $120^{\circ}$ flexion. Lim et al. (2007) found no relationship between resection amount and clinical result but suggested that liberation of coracoacromial ligament and excision of subacromial bursa were more correlated with clinical remission.

\section{CONCLUSION}

In this study, the subacromial distance is affected shoulder was shorter than healthy one. ASD increased the subacromial distance and improved clinical evaluation tests' scores in patients with chronic impingement. Moreover, a $3.58 \mathrm{~mm}$ subacromial decompression was effective for clinical remission.

\section{REFERENCES}

Atalar, A.C., M. Demirhan, Y. Kocabey and Y. Akalýn, 2001. Arthroscopic subacromial decompression: Oneto seven-year results. Acta Orthop. Traumatol. Turc., 35: 377-381.

Bezer, M., N. Aydin, B. Erol, B. Kocaoglu and O. Guven, 2004. Late results of arthroscopic and open acromioplasty. Acta Orthop. Traumatol. Turc., 38: 115-119.

Cotton, R.E. and D.F. Rideout, 1964. Tears of the humeral rotator cuff: A radiological and pathological necropsy survey. J. Bone Joint Surg., 46: 314-328.

Golding, F.C., 1962. The shoulder: The forgotten joint. Br. J. Radiol., 35: 149-158.

Jobe, C.M., 1998. Gross Anatomy of the Shoulder. In: The Shoulder, Rockwood, C.A. Jr. and F.A. Matsen III (Eds.). 2nd Edn. Vol. 1, W.B. Saunders Company, Philadelphia, USA., pp: 34-97.

Lim, K.K., H.C. Chang, J.L. Tan and B.K. Chan, 2007. Arthroscopik subacromial decompression for stage-2 impingement. J. Orthop. Surg., 15: 197-200.

Neer, C.S., 1972. Anterior acromioplasty for the chronic impingement syndrome in the shoulder: A preliminary report. J. Bone Joint Surg., 54: 41-50.

Neer, C.S., 1983. Impingement lesions. Clin. Orthop., 173: $70-77$.

Weiner, D.S. and I. Macnab, 1970. Superior migration of the humeral head. A radiological aid in the diagnosis of the rotator cuff. J. Bone Joint Surg., 52: 524-527. 